\title{
Varsistonhävitys siemenperunatuotannossa
}

\author{
Elina Virtanen ${ }^{1)}$ ja Kristian Forsman ${ }^{1)}$ \\ ${ }^{1)}$ MTT Pohjois-Pohjanmaan tutkimusasema, Tutkimusasemant 15,92400Ruukki,etunimi.sukunimi@mtt.fi
}

\section{Johdanto}

Varsistonhävityksessä pyritään tuhoamaan perunan maanpäällinen kasvusto, jolloin yhteyttäminen ja mukuloiden lisäkasvu lakkaavat. Yleisesti varsistonhävitystä käytetään perunantuotannossa mukulan kuoren vahvistamiseksi, korjuutyön helpottamiseksi ja tautien torjumiseksi. Lisäksi varsistonhävityksen avulla pystytään säätelemään perunan mukulakokojakaumaa. Tätä mahdollisuutta myös siemenperunatuotannossa yleisesti käytetään, sillä ostajat suosivat pienimpiä siemenperunaluokkia 30 - 50 millin kokoluokkaan.

Yksistään mukulakoon säätelyyn ei perunan varsistonhävitystä kuitenkaan suositella tehtäväksi, sillä se johtaa usein aikaisilla ja suurimukulaisilla lajikkeilla kasvuston tuhoamiseen täysin tuleentumattomana, jopa kukintavaiheessa olevana. Kasvun keskeyttäminen tuleentumattomana jättää sadon tärkkelyspitoisuuden alhaiseksi, ja toisaalta mukulan fysiologinen tila saattaa olla epästabiili. Lisäksi jos kuoren kiinteytymisen tai nosto- ja varastointikapasiteetin vajavaisuuden takia joudutaan nostoa viivyttämään paljon yli suositellun 10 - 14 vuorokauden, riski kasvitautien lisääntymiselle on todellinen.

Varsisto voidaan hävittää joko mekaanisesti erilaisilla murskaimilla tai kemiallisesti torjuntaaineita ruiskuttamalla sekä näiden yhdistelmällä. Mekaanis-kemiallinen varsistonhävitys on siemenperunatuotannossa yleisin hävitysmenetelmä. Varsisto murskataan ensin 30 - 40 sentin sänkeen, ja 1 - 2 vuorokauden kuluttua loput kasvinosat tuhotaan kemiallisesti. Kemialliseen varsistonhävitykseen on Suomen markkinoilla kaksi tehoainetta, dikvatti (Reglone) ja karfentratsoni-etyyli (Spotlight Plus). Muita menetelmiä varsistonhävittämiseen on varsiston nyhtäminen tai kemiallisessa varsistonhävityksessä erilaisten happojen käyttäminen. Kummastakin on vähän kokemuksia Suomen oloissa.

Tämän tutkimuksen tarkoituksena oli selvittää nykyisin siemenperunatuotannossa yleisessä käytössä olevien varsistonhävitysmenetelmien vaikutusta siemenperunan satoon ja sadon laatuun. MTT:n Pohjois-Pohjanmaan tutkimusasemalla vuosina 2001 - 2003 suoritetuissa kokeissa tutkittiin mekaanista varsistonhävitystä ja mekaanis-kemiallista menetelmää kummallakin kaupallisella aineella verrattuna luontaisesti tuleentuvaan kasvustoon. Varsistonhävityksen ajankohta, ja hävityksen ja noston välinen aika, olivat sovelluksia siemenperunatuotantotilan normaaleista käytännöistä.

\begin{abstract}
Aineisto ja menetelmät
Varsistonhävityskokeet perustettiin MTT:n Pohjois-Pohjanmaan tutkimusasemalle vuosina 2001 - 2003. Koekäsittelyt ovat Taulukossa 1. Mekaanisen varsistonhävityksen ajankohta määritettiin kasvunostojen avulla sellaiseksi, että korkeintaan $5 \%$ sadosta oli kooltaan yli 50 millimetristä. Kemiallinen varsistonhävitys suoritettiin mekaanis-kemiallisille koejäsenille 0 - 2 vuorokauden kuluttua mekaanisesta käsittelystä (Taulukko 2). Vesimääränä kemikaaleilla käytettiin 2001 ha $^{-1}$ vuonna 2001 ja vuosina $2002-20033001$ $\mathrm{ha}^{-1}$. Nosto suoritettiin vähintään kolme viikkoa ruiskutuksen jälkeen (Taulukko 2). Lannoitteena kokeissa käytettiin Perunan Y1:stä (8-5-19) typpilannoitustason ollessa $60 \mathrm{~kg} \mathrm{ha}^{-1}$ vuosina 2001 ja 2003 ja $70 \mathrm{~kg} \mathrm{~N}$ ha $^{-1}$ vuonna 2002. Koeasetelmana oli lohkottain satunnaistettu koe, jossa oli neljä toistoa. Lajikkeena käytettiin Matildaa.
\end{abstract}

Taulukko 1. Varsistonhävityskokeen koejäsenet ja käsittelyt

\begin{tabular}{l|l}
\hline Koejäsen & Käsittely \\
\hline Luontainen tuleentuminen (LT) & Käsittelemätön kontrolli \\
\hline Varsistonhävitys mekaanisesti $(\mathrm{M})$ & Varsiston mekaaninen murskaus ketjumurskaimella \\
\hline Varsistonhävitys mekaanis-kemiallisesti & Varsiston mekaaninen murskaus ketjumurskaimella ja \\
Reglonella (M+R) & Reglone -ruiskutus $\left(1,51 \mathrm{ha}^{-1}\right) 0-2$ vrk edellisestä \\
\hline Varsistonhävitys mekaanis-kemiallisesti & Varsiston mekaaninen murskaus ketjumurskaimella ja \\
Spotlight Plussalla (M+SP) & Spotlight Plus -ruiskutus $\left(11 \mathrm{ha}^{-1}\right) 0-2$ vrk edellisestä \\
\hline
\end{tabular}


Taulukko 2. Varsistonhävityskokeen päivämääriä eri vuosina

\begin{tabular}{lcccc}
\hline Vuosi & Istutus & $\begin{array}{c}\text { Kasvuston } \\
\text { tautihavainnot }\end{array}$ & Varsistonhävitys & Nosto \\
\hline 2001 & 6.6. & 3.8. & $\begin{array}{l}6.8 . \text { (mekaan.) } \\
\text { 8.8. (kemiall.) }\end{array}$ & 3.9. \\
2002 & 21.5. & 6.8. & $\begin{array}{l}26.8 . \text { (mekaan.) } \\
\text { 28.8. (kemiall.) }\end{array}$ & 18.9. \\
& & & $\begin{array}{l}\text { 12.8. (mekaan.) } \\
\text { 12.8. (kemiall.) }\end{array}$ & 2.9. \\
\hline
\end{tabular}

Kokeet hoidettiin ja havainnoitiin virallisen lajikekoeohjeistuksen mukaisesti [http://www.mtt.fi/atu/epo/ lajikekoe/koeohje.html]. Ruutusadot punnittiin ja sato lajiteltiin eri kokoluokkiin $(<35 \mathrm{~mm}, 35-55 \mathrm{~mm}$, $55-70 \mathrm{~mm}$ ja $>70 \mathrm{~mm}$ ). Tärkkelyspitoisuus ja sadon ulkoinen laatu havainnoitiin $35-70$ millisestä sadosta edelleen ruuduttaisina näytteinä. Ulkoisen laadun lisämäärityksenä havainnoitiin seittiruven määrä. Seittiruven havainnointi on sama kuin perunaruven. Ruven saastuttama pinta-ala mukulan pinnasta arvioidaan, ja mukula hylätään, jos taudin peitto on yli $10 \%$ mukulan pinnasta. Kemiallisen varsistonhävityksen teho havainnoitiin kasvuston vihreiden osien ruskettumisena neljä kertaa, 2-3, 7, 14 ja 21 vrk:n kuluttua kemikaalin käytöstä. Mekaanisen murskauksen teho arvioitiin varsiston peittävyysprosentteina pitäen vertailuajankohtana varsiston murskauksen jälkeistä tilaa.

\section{Tulokset ja tulosten tarkastelu}

Varsistonhävitysmenetelmät toimivat odotusten mukaisesti. Mekaanis-kemiallinen varsistonhävitys toimi tehokkaasti tuhoten varsiston käytännössä täysin kahdessa viikossa (Kuva 1). Torjunta-aineista Reglone oli nopeavaikutteisempi, mutta toisaalta Reglonella oli havaittavissa varren tyvestä lähtevää uutta versoa kahtena ensimmäisenä vuonna. Mekaanisen murskauksen teho vaihteli siten, että ensimmäisenä vuonna kasvusto selvästi toipui murskauksesta kolmen viikon kuluessa, mitä ei toisena vuonna tapahtunut. Vuonna 2003 mekaanisen murskauksen tehoa ei havainnoitu.

Kuva 1. Eri varsistonhävitysmenetelmien teho ja keskihajonnat koejäsenittäin neljänä havaintokertana kemiallisen varsistonhävityksen jälkeen (lyhenteet: ks. Taulukko 1)

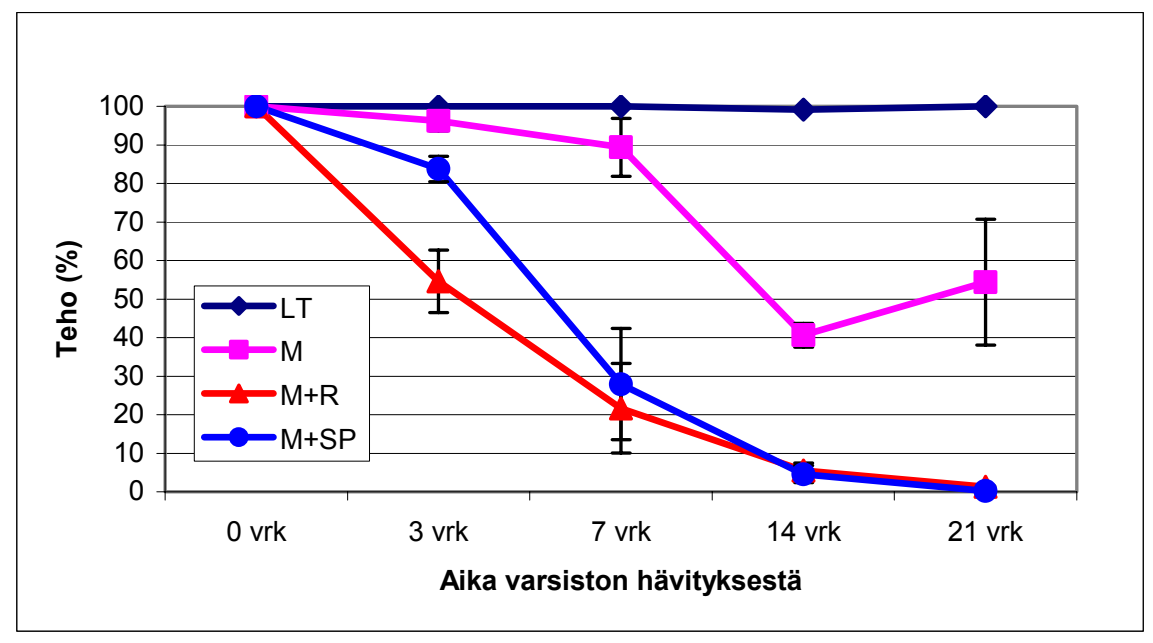

Sadon määrä on luonnollisesti suurempi kun varsistoa ei hävitetä (Kuva 2). Kasvun jatkuessa sadon tärkkelyspitoisuus pääsee nousemaan lajikkeen luontaiselle tasolle (Kuva 2). Keskimäärin mekaaninen varsistonhävitys vaikutti samalla tavalla kuin mekaanis-kemiallinen varsistonhävityskin. Vuositasolla oli vaihtelua siten, että ensimmäisenä vuonna mekaanisen varsistonhävityksen sekä sato että sadon tärkkelyspitoisuus nousivat mekaanis-kemiallisia suuremmaksi, muina vuosina eroja ei ollut. 
Kuva 2. Kokonaissato (pylväät) ja tärkkelyspitoisuus (katkoviiva) koejäsenittäin sekä niiden keskihajonnat (lyhenteet: ks. Taulukko 1)

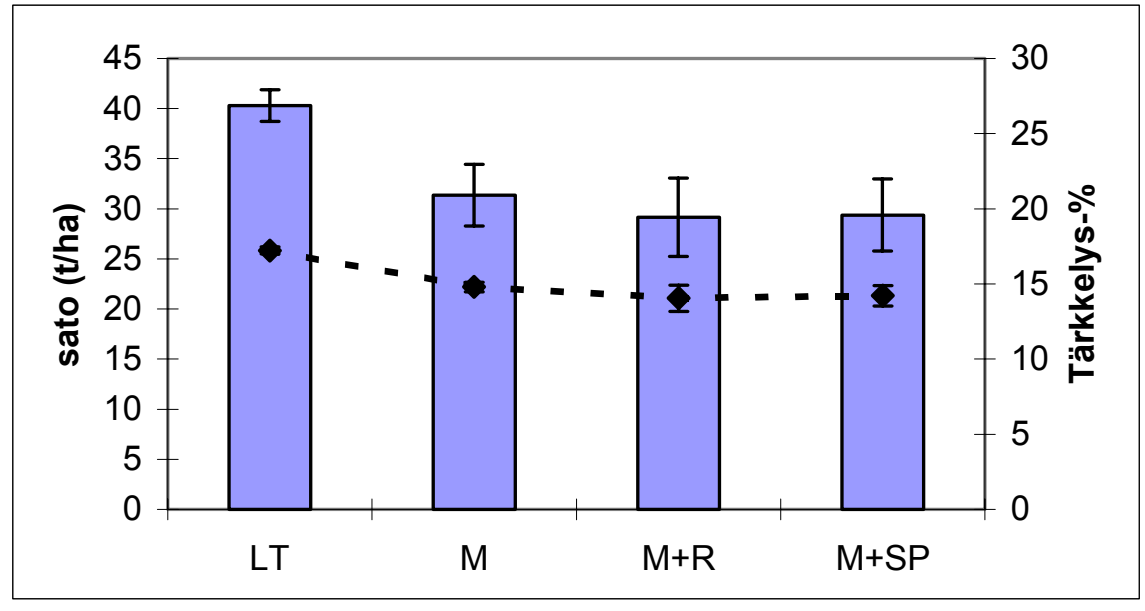

Satomäärä oli yhteydessä mukulakokoon. Alle 35 mm sadon määrä oli käsittelemättömässä koejäsenessä kaikkein pienin, $19 \%$ kokonaissadosta. Mekaanisessa varsistonhävityksessä $<35 \mathrm{~mm}$-kokoluokan osuus oli $32 \%$ ja mekaanis-kemiallisissa $36 \%$. Ero varsistonhävitystapojen välillä syntyi ensimmäisenä vuonna, kun mekaanisen varsistonhävityksen satokin oli suurempi. Vastaavasti satoluokan 35-55 mm osuus kontrollilla oli $73 \%$, kun se mekaanisella oli $64 \%$ ja mekaanis-kemiallisilla keskimäärin $61 \%$.

Perunaseittiä (Rhizoctonia solani) havaittiin kasvustossa satunnaisesti. Tautisten yksilöiden osuus oli koejäsenkohtaisesti keskimäärin $0-3,5 \%$. Eniten perunaseittiä havaittiin vuonna 2002 keskimäärin 1,5\% ja vähiten vuonna 2001, jolloin tautisia yksilöitä ei ollut lainkaan. Satomukuloissa sen sijaan seittirupea havaittiin runsaasti (Kuva 3). Seittiruven määrä vaihteli myös runsaasti koejäsenten välillä ja eri vuosina. Vuosina 2001 ja 2002 mekaanis-kemiallinen varsistonhävitys lisäsi seittirupea tilastollisesti merkitsevässä määrin muihin koejäseniin verrattuna. Vuonna 2002 myös mekaaninen varsistonhävitys lisäsi rupea käsittelemättömään verrattuna. Viimeisenä vuonna ei koejäsenten välillä ollut tilastollista eroa.

Kuva 3. Seittirupisten (saastuntamäärä $>10 \%$ mukulan pinnasta) mukuloiden osuus sadosta ja seittirupisuuden keskihajonta koejäsenittäin ulkoisen laadun havaintojen perusteella (lyhenteet: Taulukko 1)

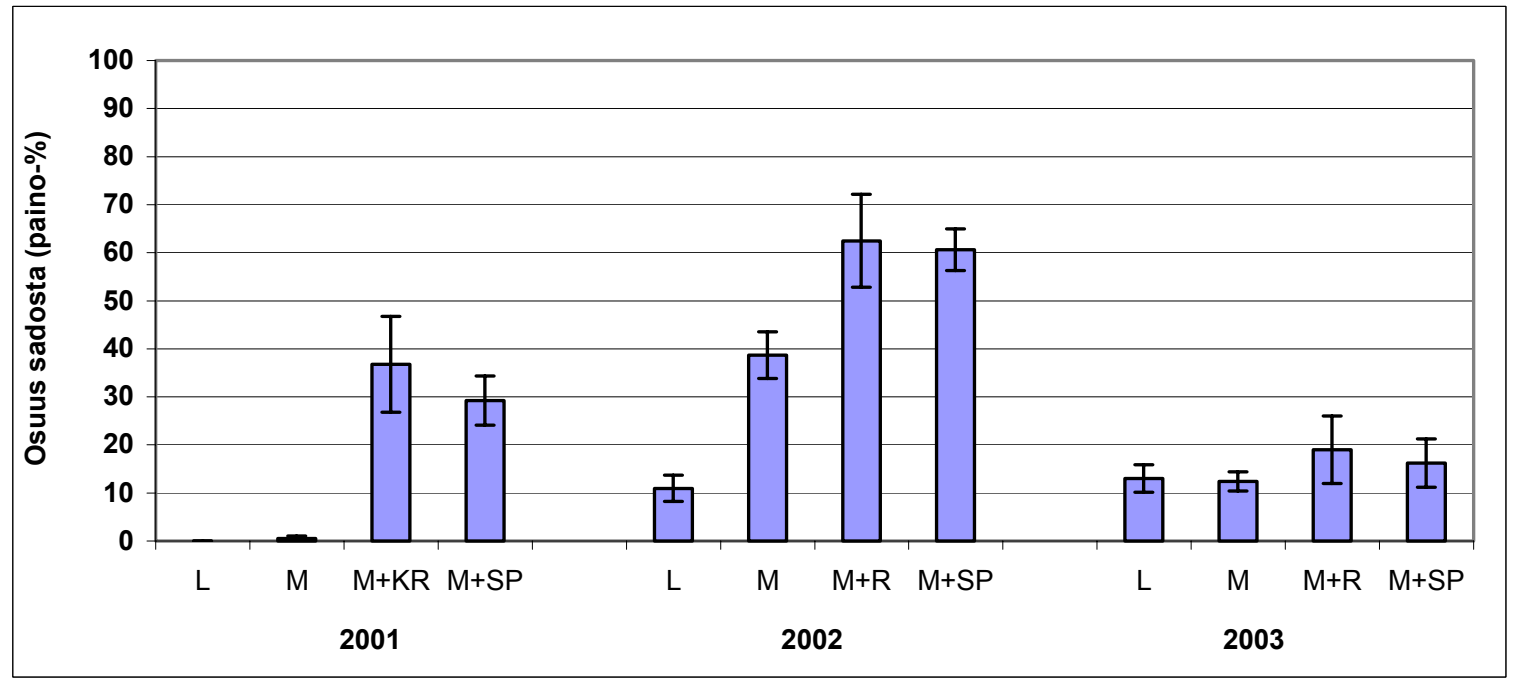




\section{Johtopäätökset}

Yhteyttäminen ja mukuloiden lisäkasvu onnistutaan tehokkaasti lopettamanaan hävittämällä varsisto mekaanis-kemiallisesti. Myös mekaaninen varsistonhävitys toimi hyvin, mutta ensimmäisenä vuonna varsistoon kasvoi kahden viikon jälkeen selvästi uutta lehdistöä. Yhteyttämiskapasiteetin uusi muodostuminen ilmeni mekaanisen varsistonhävityksen kohonneena satotasona sekä mukuloiden lisäkasvuna mekaaniskemialliseen varsistonhävitykseen verrattuna. Minään vuonna mekaaninen varsistonhävitys ei aiheuttanut kasvuston täydellistä tuhoutumista, vaan murskauksessa jälkeenjäänyt lehvästö pysyi vihreänä. Kemiallisista varsistonhävitteistä Reglone vaikutti nopeimmin, mutta Reglonen ongelmana oli varren tyveltä lähteneet uudet versot. Uuskasvu oli ensimmäisenä vuonna runsastakin, toisena vuonna satunnaista.

Varsistonhävityksen avulla pystytään säätelemään mukulakokojakaumaa, mutta tämä tehdään sadon ja sadon tärkkelyspitoisuuden kustannuksella. Varsistonhävityksen vaikutusta eri kokoluokkien painojakaumaan siemenperunantuottajan näkökulmasta ei pystytä koetulosten perusteella kuitenkaan tarkasti laskemaan, sillä havainnot suoritettiin virallisten lajikekokeiden suoritusohjeiden mukaisesti, mikä ei lajittelun puolesta ole yhteneväinen siemenperunatuotannon kanssa. Siemenperunat lajitellaan tyypillisesti kokoluokkiin 30-40 ja 40-50 milliä. Tärkkelyspitoisuuden lasku verrattuna käsittelemättömään on toisaalta seurausta tärkkelyssynteesin loppumisesta, toisaalta nesteen kertymisestä mukuloihin.

Seittirupi on perunaseitin kestomuoto, joka ilmenee mukulan pintaan kiinnittyneinä pahkoina. Perunaseitti leviää täten siemenen mukana, joten seittiruven runsas esiintyminen vähentää siemenperunan käyttöarvoa. Siemenperunan varastotarkastuksessa sallitaan korkeintaan $3 \%$ sellaista seittirupea (tai syvä- tai känsärupea), joka peittää mukulan pinnasta yli kymmenenneksen [http://www.kttk.fi]. Seittiruven kehittymistä stimuloi mukuloista vuotavat eritteet, ja siten mitä kauemmin perunaa pidetään maassa, sitä suurempi on seittiruven riski. Mekaanis-kemiallinen varsistonhävitys lisäsi seittiruven osuutta kokonaissadosta yli 30 \%-yksikköä vuonna 2001 ja noin 50 \%-yksikköä vuonna 2002 verrattuna käsittelemättömään satoon. Myös mekaaninen varsistonhävitys lisäsi seittirupea. Tämä tapahtui sellaisena kasvukautena, jona mekaanisen varsistonhävityksen teho varsistoon oli paras. Varsistonhävitys siis lisää kasvitautipainetta, eikä varsistonhävityksen ja noston välistä aikaa tulisi pidentää yli suosituksena annetun kahden viikon. 